\title{
IMAGENS AUDIOVISUAIS E HISTÓRIA DO TEMPO PRESENTE ${ }^{1}$
}

\author{
Michèle Lagny*
}

\section{Resumo}

O presente artigo redigido em francês foi apresentado em forma de conferência no encerramento do I Seminário Internacional História do Tempo Presente, promovido pelo Programa de Pós-Graduação em História da UDESC e ANPUH-Seção SC, realizado nos dias 07 a 09 de novembro de 2011, em Florianópolis/SC. Nele apresentam-se discussões sobre o interesse pelo audiovisual por parte dos historiadores, no momento em que emerge o conceito de história do tempo presente, na França.

Palavras-chave: História. Imagens audiovisuais. Tempo presente.

Na França, o audiovisual, sob a forma do cinema, torna-se uma fonte documental para os historiadores (FERRO, 1973, SORLIN, 1974) no exato momento em que nos anos 70 desenvolve-se o conceito de história do tempo presente com, em 1978-79, a criação do Instituto de História do Tempo Presente (Institut d'Histoire du Temps Présent) que assegura a continuidade do Comitê de História da Segunda Guerra Mundial (Comité d'Histoire de la Seconde Guerre Mondiale) (GARCIA, 2010, p.282-294). Dois elementos intervêm no interesse do historiador pela imagem animada: o sentimento de que ela dá conta do real e o de que o fato de ser “armazenada em uma lata” fará dela um testemunho durável. A teoria que fundamenta esta concepção será formulada mais tardiamente, em 1997, por Jean-Louis Comolli e Jacques Rancière em Arrêt sur histoire, cujo argumento é que “o cinema já está na história, já é história tentando se tornar traço visível, arquivo, espetáculo [...] Filho deste

\footnotetext{
${ }^{1}$ Tradução de Olívia Rangel Joffily. Revisão da Tradução Fábio Macedo e Mathilde Zagala.

* Professora de História da Cultura no Departamento de mediações culturais na Universidade Paris III. E-mail: michelelagny@sfr.fr
} 
século [...] ele é ao mesmo tempo o empreendedor e o arquivista, o ator e a memória”. “A fatalidade documental do cinema” quer que o objetivo da câmera seja totalmente objetivo, no sentido que "ele não tem necessidade de querer o presente. Ele não pode deixar de sê-lo. Ele é sem memória e sem cálculo. Sem ressentimentos, portanto”. Guardando “memória por si mesmo”, ele pode oferecer testemunhos diretos de uma realidade no presente, monumento, portanto, que “contém memória pelo próprio fato de apenas ter se preocupado com seu presente” (COMOLLI; RANCIÈRE, 1997, p. 13, 48, 55) e que o historiador, ao fazê-lo falar, o transformará em documento cujo valor de verdade caberá a ele avaliar e cujo significado caberá a ele construir.

\section{Um interesse recíproco, mas desarticulado}

\section{O cinema: "uma história em construção"}

É bem este sentimento que, numa ingenuidade inicial resultante de certa duplicidade, leva o cinema, desde seu início, a se interessar pela história imediata, bem antes da história se interessar pelo cinema. Dos operadores Lumière ao cinema-verdade e às reportagens ao vivo, das encenações oficiais dos grandes acontecimentos às imagens de guerra ou de movimentos sociais, das pesadas câmeras dos primeiros tempos aos telefones celulares contemporâneos, a apreensão audiovisual é considerada indiscutivelmente como testemunho porque ela "mostra" o que se passa no momento em que a história acontece. Assim, o cinema revela de imediato um interesse pela história do tempo presente, como enaltecem frequentemente os promotores do início do século XX apresentando suas "visões” bem como seus "noticiários de atualidades”; alguns chegam a imaginar que grandes homens do passado, como Napoleão, devem se remoer em suas tumbas por não terem podido se beneficiar desta engrenagem de celebridade! (LAGNY, 1999, p. 329-352) Ao fixar o momento pela imagem, ele se torna fonte para uma história imediata, primeiro esboço de relato do presente no presente. Desde os anos 70, antes que as "novas imagens" transmitidas pela internet interviessem diretamente na história imediata, ele foi destronado pela televisão, transformada na verdadeira fonte audiovisual de massa, particularmente nos domínios em que ela já venceu o cinema (os jornais televisivos substituindo as atualidades cinematográficas desde os anos 60) ou tende a suplantá-lo (documentários de investigação). 


\section{Os historiadores se apropriam das fontes audiovisuais}

É justamente quando, nos anos 60-70, começa a ser formulada a noção de história do tempo presente que certos historiadores acabam, após um período de desprezo pelo audiovisual, percebendo que podem, graças a ele, não apenas utilizar as tomadas ou as montagens de imagens destinadas à informação imediata, à ação política ou sua justificativa, como eles fazem com a imprensa, mas servir-se dele para interrogar a forma com que o momento presente é apresentado ou pela qual determinados atores querem que ele seja percebido. É nesse período que eles vão se interessar pelas fontes cinematográficas, por seu valor documental e pelos cuidados que devem ser tomados ao utilizá-las. É necessário aqui prestar homenagem a Marc Ferro que desempenha o papel de precursor. Após um primeiro reconhecimento oficial em 1967, com a projeção no Instituto Francês de História Social (Institut Français d'Histoire Sociale) da montagem que ele realizou para a televisão a partir de notícias cinematográficas, L’année 1917. Ele introduz assim os Arquivos cinematográficos na parafernália dos historiadores do século XX e “a história se abre ao cinema”. Desde 1968, num artigo publicado na revista dos Annales, ele destaca que "para a época contemporânea, ao menos” o interesse de dispor de "documentos de um tipo novo, de uma linguagem diferente” e reclama o depósito legal para a construção de "arquivos de nosso tempo". "Embora o cinema não seja toda a história, sem ele não poderia existir conhecimento de nosso tempo” (FERRO, 2011, p.173-186). O que não exclui a desconfiança constitutiva da psique dos historiadores e, portanto, a análise crítica. Se hoje a era do desprezo foi superada, subsiste a necessidade de desenvolver instrumentos para tratar estas imagens, que parecem oferecer resultados inesperados quando as comparamos com os resultados obtidos via outros instrumentos (discursos, imprensa, etc.), como nos mostra Ferro numa famosa análise das Actualités de Petrograd em 1917, na qual os operários não aparecem, contradizendo assim o discurso oficial sobre a revolução proletária (FERRO, 2011, p.221-225).

\section{Fontes diretas, porém midiatizadas}

Os historiadores do tempo presente utilizam principalmente as produções cinematográficas ou televisivas com função informativa ou documental, tomadas diretas ou montagens, frequentemente tentados pelos discursos ideológicos ou propagandísticos, às 
vezes mesmo pelo discurso histórico. Sem chegar a excluir os filmes de ficção que tratam de problemas do presente de interesse histórico que, embora mais marcados pelo imaginário, podem ser lidos como sintomas de sua época: são sobretudo essas as fontes que eu pretendo abordar aqui. Podemos caracterizá-las por imperativos comuns.

\section{Copresença dos atores}

Os limites cronológicos da história do tempo presente colocam evidentemente um problema que nem sempre é claramente solucionado. Em princípio, a história do tempo presente supõe uma copresença dos atores, o que poderia limitar sua duração a uma ou duas gerações. Os recursos preferidos da história imediata, o testemunho oral ou as diversas formas de imprensa, deveriam supostamente garantir a homogeneidade cronológica, porque são caracterizados pela contemporaneidade da testemunha e de seu entrevistador, assim como dos fatos e de seu comentário imediato pelos jornalistas (FRANCK, 1992; RIOUX, 1992). O audiovisual acentua esta coexistência, pois a filmagem é contemporânea à cena filmada e produtora do vestígio de uma relação real entre duas presenças, a dos acontecimentos ou testemunhos filmados assim como daqueles que as filmam (cineastas e operadores, eles mesmos às vezes aparecendo nos registros) embora, como veremos adiante, seja frequentemente necessário produzir um trabalho prévio de encenação.

Sendo próprio do registro poder fixar os fatos e gestos os quais ele testemunha na “película”, doravante substituída pelo “digital”, ele tem a vantagem de poder se conservar (pelo menos durante certo tempo, ainda mal definido, mas cobrindo ao menos uma ou duas gerações) e de funcionar como uma reserva imediatamente utilizável. Em particular, a filmagem imprime ao testemunho oral, fonte favorita da história do tempo presente, uma visibilidade que o registro sonoro, que deve ser transcrito, não permitia. Podemos ver isso num caso magistralmente analisado por Sylvie Lindeberg e Anette Wieviorka (2008, p. 12491273) a respeito do filme de Leo Hurwitz que, no momento do processo de Eichmann, em Israel, em 1961, monta diretamente em estúdio as imagens registradas no tribunal, elas mesmas destinadas a uma difusão televisiva e filmadas por quatro câmeras de vídeo de cuja organização visual ele próprio participou. Alguns documentários de investigação possuem uma função crítica quanto a estes testemunhos, seja pelo objeto que mostra a filmagem, seja pelo objeto construído pela montagem. Assim, no filme Le Chagrin et la Pitié de Marcel Ophuls, 1969, que procura abordar como os franceses reagiram durante a ocupação nazista, destacamos uma cabeleireira que, negando diante da câmara os atos de colaboração de que foi 
acusada, torce as mãos ao falar introduzindo uma dúvida sobre sua sinceridade. Igualmente, no momento em que dois velhos professores dizem não mais se lembrar quais eram exatamente os jovens resistentes em Clermont-Ferrand, um movimento de câmera mostra uma placa comemorativa: enquanto os protagonistas pretendem, um pouco constrangidos, que se trata de mortos da guerra de 1914-18, a câmera se move e nos mostra sobre a placa os nomes de 1939-45. Nos dois casos, começamos a suspeitar dos testemunhos e imagens originais e até da própria neutralidade da pesquisa histórica e somos levados a nos questionar não apenas sobre os vestígios dos comportamentos dos franceses durante a guerra, de que o filme trata, mas sobre o ponto de vista que se procura imprimir ao fim do regime de De Gaulle.

Outro ator, desta vez externo, mas suscitado pelo filme, também intervém: o espectador visado pelos produtores. Raramente presente na imagem, algumas vezes interpelado diretamente pelo “olhar da câmera” (Lumière, Congrès des photographes), ele é mais frequentemente solicitado pelo eixo do olhar dos personagens, especialmente pelas conexões de montagem que lhe fazem ver no lugar deste (focalização interna). Ele também é solicitado pela construção e as variações do quadro que, fixo ou móvel, articulando campo, profundidade do campo e fora do campo, “elabora [...] um olhar a partir da mecânica elementar da pulsão de ver” (COMOLLI; RANCIÈRE, 1997, p. 19). Ele ultrapassa virtualmente, no momento da projeção, a fronteira entre o seu lugar e a tela, para se tornar, ainda que temporariamente, um contemporâneo ao evento filmado.

Esta tripla copresença mantém assim a ilusão de um presente já passado que é também um passado sempre presente na tela. O historiador ou o operador já desapareceram, mas seu testemunho e sua voz permanecem vivos na imagem e os fatos parecem sempre diretamente apreensíveis por novos espectadores. Assim, o audiovisual atribui uma sobrevida indeterminada à história imediata, aumentando sua duração, com o risco de complicar a temporalidade histórica.

\section{Papel da midiatização}

O papel de testemunha do audiovisual é cada vez mais facilitado pela evolução das técnicas de difusão e de registro. Após o início laborioso do "heroico cinematógrafo” (Laurent Veray (2002; 2011), sobre os arquivos da Grande Guerra), em particular desde a Segunda Guerra Mundial, os repórteres utilizam um material cada vez menos pesado para registrar as atualidades. De início as câmaras 35 ou 16 mm, depois os gravadores portáteis permitindo que equipes restritas captem eficazmente os acontecimentos, e funcionem como equipes de 
imprensa, criando um verdadeiro cine-jornalismo. Assim, o russo Roman Karmem "um cineasta a serviço da revolução” (BARBERIS; CHAPUIS, 2002) testemunha no presente, durante sua vida, tanto a Guerra Civil Espanhola, desde 1936, como a libertação dos campos de concentração ou a capitulação da Alemanha nazista em Berlim em 1945, e realiza documentários ao vivo sobre a batalha de Dien Bien Phu, no Vietnã, em 1954, assim como sobre o desembarque na Baía dos Porcos em Cuba, em 1961. Desde a Segunda Guerra Mundial grandes diretores recebem encomendas de governos ou do exército americano (por exemplo, a série Porque combatemos, de Capra). Alguns deles tornam-se verdadeiros correspondentes de guerra, cujos filmes são projetados nas telas dos cinemas e às vezes censurados quando são julgados demasiado “realistas” - como aqueles de John Huston no Pacífico em 1943 e, sobretudo, na Itália em 1945, The Battle of San Pietro, apresentado com cortes, e, mais tarde, em 1946, Let there be light, um documentário sobre tratamentos psiquiátricos de veteranos que só viera a público em 1981.

A transmissão dessas imagens emprega diferentes mídias (inicialmente projeções de cinema, e, mais tarde, principalmente a televisão e a internet), que constituem, elas próprias, fontes privilegiadas para a história do tempo presente. Extremamente distinta e variada, a depender de seus suportes midiáticos, ela engendra às vezes desdobramentos do original e uma transformação de seu status enquanto fonte. As tomadas diretas, frequentemente breves e fragmentadas, podem ser conservadas em arquivos e consultadas sob controle. Contudo, aquelas transmitidas imediatamente na internet (YouTube, Dailymotion, Facebook e outros) e disponíveis simultaneamente em todos os monitores de TVs e computadores do mundo, transmitem de maneira mais ou menos anônima as imagens de acontecimentos que fazem a história imediata, estando acessíveis diretamente e na maioria das vezes sem controle. Foi assim no caso da "Primavera Árabe” em 2011, tanto como no dos acontecimentos do 11 de setembro de 2001, cujas imagens são reapresentadas dez anos mais tarde em uma comemoração destinada a mantê-las em uma "história do tempo presente” que já não é mais propriamente imediata. Em um segundo nível, com efeito, primeiro o cinema e a seguir a televisão praticam edições de suas imagens, sob a forma de noticiários cinematográficos e mais tarde jornais televisivos e, por outro lado, documentários informativos, propagandísticos ou memoriais: assim, as fontes primárias, as imagens originais, são tomadas de uma fonte secundária, mais ou menos posterior à filmagem. 


\section{Q̨uestões e limites}

Perguntamos-nos às vezes sobre o interesse dessas imagens, às quais se atribui muito frequentemente uma função apenas ilustrativa, já que até hoje o cinema foi pouco utilizado em trabalhos históricos. Entretanto, suas funções oferecem possibilidades bastante vastas enquanto documentos de base para os historiadores do presente.

\section{Testemunhar}

É o primeiro objetivo do registro do presente, seja ele mais ou menos falsificado, seja tratando da informação (atualidades), de pesquisas ou de análise (sob a forma de montagens documentárias, ou até de ficções do imediato) para fixar um momento que parece importante e alimentar a imagem do presente e, depois, uma futura memória. Estes testemunhos são, como já vimos, de duas ordens. De preferência, para os historiadores, tomadas diretas de atualidades destinadas à informação e apresentadas, seja já montadas, nos noticiários cinematográficos ou nos jornais televisivos, seja de forma fragmentada, doravante diretamente na internet. Filmes também podem reorganizar esses arquivos, seja numa perspectiva estética, seja com um objetivo ideológico (um e outro estreitamente ligados). Como falei de Hurwitz e de seu filme-arquivo realizado na época do processo de Eichmann, podemos pensar igualmente no de Rony Brauman e Eyal Sivan que tentam em 1998, uma geração (37 anos) depois dos testemunhos diretos, uma nova apresentação deste processo em Un Spécialiste, que foi frequentemente atacado pelas trucagens destinadas a melhorar o áudio defeituoso, bem como, por sua montagem tendenciosa.

Esta preferência pelas “imagens do real” não exclui contudo os filmes de ficção, apesar da tradicional antinomia entre História e ficção, igualmente destacada pelos textos escritos, quando nos interrogamos sobre o papel que o historiador pode atribuir ao romance (NORA, 2011). Pensamos nos filmes inseridos em seu próprio presente, como o foram no fim da Segunda Guerra Mundial, em particular, para tomar um exemplo amplamente estudado, o do neorrealismo italiano. Podemos ver isso com os filmes de Rossellini em sua Trilogia de guerra: Roma città aperta (1945), Paisà (1946) e Germania anno zero (1947), os quais eu apenas mencionarei os títulos. 


\section{Contar a História no presente}

Graças a suas capacidades narrativas e discursivas ligadas à montagem, o filme participa diretamente da invenção de uma forma de história audiovisual, construindo relatos e análises históricas de momentos cuja memória ainda está viva entre espectadores e autores. Ele permitiu, ao longo do século XX, particularmente após o choque da Segunda Guerra Mundial, prefigurar esta história do tempo presente que os historiadores refinarão depois. Acabei de citar Le chagrin et la pitié, mas outro filme muito famoso dos anos 60 é o de Frédéric Rossif, Mourir à Madrid (1962), que relata a Guerra da Espanha. Os dois, montados menos de uma geração depois dos fatos, surgem como precursores da construção de um relato histórico do tempo presente e foram, como tal, amplamente apreciados, bem como, vivamente discutidos.

Os filmes históricos de reconstituição, assim como as ficções históricas, apresentam uma tentativa de relato e mesmo de análise histórica cujo registro oscila do esforço de exatidão à fantasia mais descabelada. Em todo caso, a ficção é frequentemente introduzida na reconstituição, mesmo séria, da história do presente, como nos dois famosos filmes de Eisenstein - O Encouraçado Potemkin, rodado em 1925 para comemorar os acontecimentos de 1905, (FERRO, 2011, p. 227-231) ou Outubro, produzido em 1927 e abordando os acontecimentos de 1917 (LAGNY; ROPARS; SORLIN, 1979). Alguns episódios são inventados, mas podem se tornar reveladores das forças profundas ocultas pela fragmentação e insuficiência de documentos e tornar a História inteligível, e até sustentar uma tese historiográfica. No entanto, as ficções históricas sobre o presente imediato, mesmo de qualidade, provocam frequentemente uma impressão de mal-estar que incomoda os historiadores. Talvez por motivos ideológicos, mas também por razões técnicas. Por exemplo, dentro de um dado gênero, como o biográfico de "grandes homens", é difícil encontrar, seja qual for seu talento, atores com credibilidade para representar os personagens conhecidos por todos, mesmo já mortos. É bem possível construir um personagem do passado pouco parecido com o original, como fez Rossellini em La Prise du pouvoir par Louis XIV (filme para a televisão em 1966), pois nesse caso pouco importa, já que não conhecemos diretamente seus traços. No entanto, é mais difícil fazer os atores desempenharem papel de chefes de estado cujas fotos ainda estão por toda parte. Para não citar W de Oliver Stone, sobre George W. Bush em 2008, podemos ver isso na França no recente filme de Guédiguian, Le promeneur du Champ de Mars (2005) sobre François Mitterrand, estrelado por Michel Bouquet e, melhor 
ainda, em La Conquête de Durringer e Rothman sobre a ascensão de Nikolas Sarkozy, ainda em circuito, estrelado por Denis Podalydes e apresentado no Festival de Cannes em maio de 2011. Os historiadores podem transigir sobre o "verdadeiro”, que nunca estamos seguros de atingir, mas não sobre o "verossimilhante”!

Aliás, as ficções históricas parecem construir às vezes uma história do presente propriamente cinematográfica, como nos mostra Pierre Sorlin (1991, p.63-70) quando ele destaca a que ponto as representações ficcionais da Resistência no cinema europeu, cujas primeiras imagens foram construídas pela Inglaterra em Secret Mission, em 1942, funcionam muito mais sobre as referências cinematográficas do que estas sobre a realidade. Isto vale ainda mais para as ficções posteriores aos acontecimentos de que tratam, como as que floresceram sobre a Ocupação da França na época do movimento chamado de "retrô" nos anos 70-80, descrevendo os clandestinos de L'armée des Ombres (Jean-Pierre Melville, 1969), os judeus verdadeiros (Michel Drach, Les violons du bal, 1974) ou falsos (Joseph Losey, Mr. Klein, 1976) os aproveitadores e os delatores (Louis Malle, Lacombe Lucien, 1974, Edouard Molinar, Au bon beurre, 1980, François Truffaut, Le dernier métro, 1980). Para sair do cinema francês, tomemos o exemplo de um filme de Axel Corti, em 1986, Welcome in Vienna, que descreve a desmoralização, quarenta anos antes, na capital austríaca ocupada pelos Aliados. Nele, encontramos planos diretamente extraídos de Germania anno zero (1947), no qual Rossellini deplorava, ao vivo, a perda de valores devido ao nazismo. Em particular, com um enquadramento em travelling no qual um dos heróis, com ilusões políticas ainda infantis (ele acredita no comunismo!), desce de um bonde no momento de encontrar uma delegada soviética, que o desencorajará; este bonde evoca àquele que o pequeno Edmund tomava na Berlim em ruínas no momento de seu reencontro com seu ex-professor nazista que o abandonará. A referência é assinalada pela presença de um garoto que corre atrás do bonde em Viena, como o fazia Edmund em Berlim.

Não obstante, o filme, montagem de arquivo ou ficção, está submetido às mesmas distorções cronológicas que o historiador, como mostrou Michel de Certeau, em L'Écriture de l'histoire (1975, p.27-161), revelando que, sejam quais forem os esforços de honestidade intelectual, ele só pode pensar em função de seu mundo. Indício de uma forma de representar um presente recente, mas passado, o relato histórico audiovisual fornece um testemunho tanto do presente no qual ele é realizado, quanto daquele que ele tenta evocar, nos colocando deliberadamente numa temporalidade já desdobrada. Essa é uma de suas formas de "falar sempre no presente”. 


\section{Consideráveis problemas críticos}

Sejam quais forem suas formas e suas ambições, todos estes tipos de realizações exigem uma dupla análise crítica. Uma é familiar aos historiadores, a do valor das fontes, vestígios do tempo dos acontecimentos ainda próximos ou até imediatos, ao mesmo tempo mais fácil pela proximidade do tempo e mais difícil pela ausência de recuo, durante muito tempo visto como proibitivo. A outra diz respeito às particularidades da linguagem audiovisual, mesmo se doravante os historiadores possam se formar nela tanto quanto na crítica dos documentos escritos: a das próprias imagens e a das montagens ou reconstituições nas quais as imagens são frequentemente utilizadas com uma defasagem temporal mais ou menos significativa.

\section{Encontrar, autenticar, contextualizar}

É a prática habitual dos historiadores: como para toda forma de história também é preciso sair à caça das imagens originais, avaliar sua autenticidade controlando sua proveniência e avaliando sua qualidade técnica visual e sonora: uma sensibilidade quanto à granulação da imagem e suas variações permite, por exemplo, descobrir as manipulações técnicas ou as intrusões da ficção no arquivo.

A caça às fontes não é necessariamente simples, apesar do desenvolvimento dos depósitos de arquivos filmados e escritos. Podemos constatar isso no livro de Sylvie Lindeperg, Nuit et brouillard, un film dans l'histoire, sobre o documentário realizado em 1955 por Alain Resnais e Roland Cayroll, sob a encomenda dos historiadores da Segunda Guerra Mundial. Ela o aborda ao mesmo tempo em seu próprio presente (a apenas dez anos de distância do fim dos campos) e na evolução de sua recepção, na perspectiva de uma “história dos olhares” (LINDERPERG, 2007). Cinquenta anos depois ela precisou reencontrar e analisar os traços dos primeiros criadores do projeto e, em seguida, dos diretores do filme: através de correspondências, dossiês de produção, cadernos de filmagem, notas de montagem, entrevistas, bem como, através dos "arquivos" filmados em processo de constituição no pós-guerra, da Holanda à Polônia. Ela retraça as condições de elaboração do filme nos anos 50: da redação de um roteiro frequentemente remanejado, das vicissitudes da filmagem polonesa meio caótica e do que ocorre na “câmara negra de montagem”. Após uma 
análise do documentário, que joga com a alternância entre o presente atual em cores e o presente passado em preto e branco, ela aborda igualmente os seus usos sucessivos no tempo e no espaço. Quando a sua pesquisa termina, compreendemos como um "filme historiador" que "trabalha a distância e a irredutível separação com o passado" o torna, no entanto, ainda presente para o espectador: “lugar portátil de memória” que será incansavelmente questionado no presente e cujos efeitos podemos ver numa reportagem sobre a escola realizada em 1994 (Mariana Otero, La loi du collège).

\section{Distinguir o verdadeiro do falso na imagem}

É igualmente um trabalho crítico a que os historiadores estão habituados nos documentos escritos, e ao qual Lindeperg, na parte “arquivística” de seu livro, promove o estudo de cada uma das imagens de arquivos datadas da guerra de 1939-45 (onde, entretanto, insinuam-se algumas tomadas provenientes de uma ficção). Ela mostra todas as falsas atribuições da época, mais ou menos reconduzidas nos comentários sobre o filme, e as numerosas reutilizações posteriores de alguns destes fragmentos, que migram mais tarde de uma obra para outra.

Sem discutir a questão colocada por Godard, para quem a imagem é apenas uma imagem e não uma imagem precisa, é preciso dizer que até bem recentemente as dificuldades técnicas da filmagem ao vivo tiveram ampla influência sobre a veracidade da imagem. Às vezes isso foi remediado de forma audaciosa pela "reconstituição imediata”, preparada antes do acontecimento quando ele é previsível: para dar um exemplo engraçado, desde o início do cinema, Le couronnement d'Edward VII foi realizado por Méliès nos aposentos de seu estúdio em Montreuil alguns dias antes do dia previsto para a cerimônia, para projetá-lo na mesma noite, em junho de 1902. Ele mostrou-se mais antecipador do que ele queria, pois como o rei estava doente, o coroamento foi adiado por dois meses. Assim, o filme poderia ter tido o nome de “Aconteceu amanhã”! Mesmo as imagens dos Lumière, espécie de cinejornal realizado por operadores do mundo inteiro “ao vivo”, são frequentemente semirreconstituídos, pois o fardo da câmara e a pequena duração das bobinas exigiam certa organização e a utilização de diversas trucagens que, aliás, contribuíram para o desenvolvimento da linguagem cinematográfica (GAUDREAULT, 2008).

Além destas necessidades técnicas e apesar do incessante progresso das ferramentas e do material cinematográfico, o uso previsto para estas imagens, não apenas consideradas como meios de informação, mas também como armas de propaganda, justificam senão o 
emprego de reconstituições, mas ao menos de "preparações”, que instigam por sua vez uma grande desconfiança. Isso é particularmente sensível para as imagens de guerra destinadas às notícias: o “ao vivo” é, neste caso, uma sábia combinação entre tomadas de campo e encenação das imagens (às vezes reconstituídas nos bastidores, especialmente necessárias pois os atores, os soldados, estão constantemente ameaçados de uma morte que se prefere não mostrar demasiado na tela). Laurent Veray propõe a esse respeito uma análise crítica em L’héroïque cinématographe, onde ele organiza a partir e a propósito da guerra de 14-18, uma montagem paralela de atualidades francesas e alemãs (seja utilizadas nas notícias então divulgadas, seja conservadas sob a forma anterior à montagem, mas censuradas na época) acompanhadas de um comentário em off extraído de “cartas” inventadas por dois operadores que nunca vemos, um francês outro alemão, e cujas vozes são "representadas". Com esta forma secundária de história audiovisual, ele nos faz descobrir, para além do que os noticiários queriam mostrar, outros elementos que deveríamos ignorar, entre os quais, como eram “fabricados” esses noticiários.

Estas práticas do início do cinema já foram bem estudadas, mas muitas dessas ocorrências de “semitrucagens pró-cinematográficas” podem ser analisadas tanto nas fontes originais quanto nas montagens documentárias que elas alimentam. O prestígio dos arquivos é tal que quando não os possuímos ou quando eles estão perdidos, o cineasta procura reinventálos, utilizando “falsos arquivos” como fez Pierre Beuchot sobre o regime de Vichy em Hôtel du Parc (1992). As montagens documentárias da época são particularmente falseadas, como nos mostra Bertin-Maghit quando ele revela todos os meios utilizados para a eficácia da propaganda, as transformando assim em “documentirosos” (BERTIN-MAGHIT, 2004). Nos dias de hoje, não apenas os pronunciamentos oficiais, as visitas de chefes de Estado, as encenações de debates eleitorais, mas também os grandes movimentos de massa e os combates diversos são falseados ou pré-fabricados, ou ao menos reorganizados e até remanejados diretamente na montagem. Às vezes, no entanto, a notícia pode fazer uma entrada sensacional e inesperada como no assassinato de Kennedy em 1963 (registrado em câmera super-8 de Abraham Zapruder, dos “26 segundos” que abalaram a América) (THORET, 2003) ou os aviões atingindo as Torres Gêmeas em 11 de setembro de 2001; mas nesse caso, as imagens, menos calculadas, são frequentemente testemunhas truncadas, que tanto historiadores como investigadores têm dificuldades de relacionar e analisar. Sem contar as trucagens imediatas permitidas pelas novas tecnologias digitais. 


\section{Ler o audiovisual}

Outra obrigação para todos os historiadores consiste em tornar-se capaz de ler estas fontes de imagens de forma ao mesmo tempo produtiva e crítica. $\mathrm{O}$ audiovisual, com efeito, não tem exatamente as mesmas modalidades de produção de sentido que a escrita. Sem entrar na apresentação do que se tornou, há muito tempo, sob influência dos linguistas, uma disciplina completa, a análise cinematográfica, é necessário lembrar a necessidade do aprendizado das formas da escrita cinematográfica: da qual, enquanto historiador, Sorlion foi um dos pioneiros, notadamente com o estudo de Ossessione (Visconti, 1943) desde 1977 na Sociologie du Cinéma (SORLIN, 1977, p.151-198). Mesmo que não estivermos particularmente interessados neste tipo de análise, a observação, desde que se tenha um pouco de sensibilidade estética e interesse pela evolução das tecnologias, não exige uma especialização avançada para decifrar um modo de expressão que tem formas criativas, mas também frequentemente codificadas e às vezes congeladas.

Que a imagem seja feita em reportagem, em locais onde a organização não é controlada diretamente pelo cameraman, ou que ela seja pré-fabricada (no estúdio ou externamente) para a rodagem de um filme cujo recorte é mais ou menos preparado, são os enquadramentos, a iluminação e a montagem que lhe imprimem forma e sentido. Em um documentário que lhe foi consagrado pelo canal de televisão franco-alemão Arte, em 1993, sobre o Triomphe de la Volonté (1935), Leni Riefenstahl explica como a multiplicação das câmeras permite destacar o carisma do líder e a ordem disciplinada da multidão; como a alternância entre os planos do Führer (frequentemente de baixo para cima) e os da multidão (de cima para baixo) atribuem ao primeiro poder absoluto sobre as reações da segunda, enquanto a trilha sonora, sem comentários em off, vêm reforçar os efeitos afetivo e emocionais. Portanto é necessário fazer a análise interna do documento, da construção dos planos, bem como da montagem e das regras narrativas utilizadas durante o relato.

Com efeito, assim como no estudo da imagem, é inevitável trabalhar a estrutura da história contada, da narrativa, especialmente da sua organização no espaço e no tempo, assim como da questão do ponto de vista adotado (interno ou externo); esses pontos foram abundantemente abordados pelos narratólogos tanto no cinema quanto na literatura. A questão do ponto de vista é tão importante para os historiadores que ela levou Marc Ferro a criar uma classificação, notadamente para os filmes históricos: ele distingue quatro posições de acordo com a localização do ponto de vista do filme, “do alto” (do ponto de vista dos poderosos), “de 
baixo” (do ponto de vista dos oprimidos), “do interior” (se o autor está abertamente implicado), ou "do exterior” (construindo o objeto social ou político em função de um modelo) (FERRO, 1977, p.224-226). Como vemos, o peso e a diversidade dos procedimentos a serem utilizados explicam parcialmente o uso tardio e ainda limitado pelos historiadores, tanto do cinema (considerado frequentemente como uma arte) como do audiovisual (considerado principalmente como um meio de comunicação).

\section{Uma outra história}

As imagens fonte, assim como as tentativas de história audiovisual, reforçam certas características que afetam a história do tempo presente, notadamente sua dimensão factual e seu poder emocional.

\section{O acontecimento transformado em espetáculo}

O audiovisual, afeiçoado ao espetáculo, favorece "o retorno do acontecimento" analisado por Pierre Nora em 1974 (1986, p. 212), como consubstancial a uma história do presente, bem como a valorização dos personagens (pequenos ou grandes) que desempenham papéis em primeiro plano. Isto se deve a boas razões: na medida em que o histórico é precisamente o que é digno de ser destacado e retido ele tem a vantagem de poder mostrar imediatamente os “momentos” tidos como cruciais e os protagonistas importantes, sejam eles personalidades do mundo da política, entre os quais alguns são excelentes atores (podemos citar aqui Lula!), ou massas revolucionárias, ou simplesmente contestatórias, como neste ano de 2011 as dos diferentes “indignados” de diversos países. Antes de se tornar histórico, quando se pode avaliar suas consequências, como destacava Nora, o acontecimento é midiático e são então as imagens que o constituem como tal, seja pela encenação preparada do que o poder quer valorizar, seja pelo surgimento brutal do inesperado frente às câmaras. Filmar uma tomada de poder, um coroamento, uma cerimônia de posse de chefe de governo, de negociações ou assinaturas de tratados de paz, potencializa o alcance destas representações, cuja organização é minuciosa na medida em que é necessário evitar qualquer passo em falso frente às câmeras de televisão. A surpresa (“revoluções árabes”, por exemplo) provoca ao contrário uma repetição em série das imagens iniciais ou então outras, derivadas, que atribuem ao acidente imprevisto seu status de evento antes mesmo que consigamos fazer 
a análise que determinará sua importância. No passado, procurava-se fixar visualmente a lembrança de um acontecimento (relato, sobretudo quadros), mas a produção do texto ou da imagem sendo posterior à realização, permitia que se avaliasse seu alcance antes de colocá-lo em cena por meio de uma representação! O “ao vivo” autorizado pela câmera propõe uma leitura imediata, antes mesmo de poder julgar a real importância do fato assim fixado, e faz correr o risco de uma multiplicação de eventos artificiais. Organizada ou não, esta proliferação por um lado favorece o sensacionalismo e por outro confere, às vezes, à história oficial do tempo presente o caráter de uma “crônica cerimonial” (BAECQUE; DELAGE, 1998, p.8) provocando tédio devido à repetição dos mesmos tipos de cena, ao qual se agrega frequentemente a impressão, quando assistimos às notícias, que estamos sendo enganados (não nos mostram tudo).

Esta dominação do fato espetacular não exclui as possibilidades de uma história do tempo presente mais social ou mais familiar. Outro aspecto interessante do audiovisual diz respeito à capacidade do filme de descrever imediatamente o cotidiano (ainda que seja feito por imagens recompostas) e a revelar "a temporalidade particular onde se desenvolve a história das pessoas por mais comuns que elas sejam”, autorizando a irrupção de seres singulares no relato do conjunto da história (FAERGE, 1998, p.111-125). No entanto, é sempre necessário que um acontecimento, por mínimo que seja, autorize a apreensão do propósito ou permita justificar as investigações audiovisuais sobre as atividades e os comportamentos dos grupos sociais na família, no trabalho ou em suas práticas culturais. Desde La sortie des usines Lumière ou Le déjeuner de Bébé, filmar um microacontecimento social ou familiar tornou-se rapidamente um hábito, reforçado pelas câmeras digitais e os telefones celulares que permitem "ao mesmo tempo a tomada, a recepção e a difusão [... e] realizam o sonho de comunicação imediata por meio da imagem animada” (ODIN, 2011, p.8).

\section{O peso do afeto}

Para além do factual, os historiadores do presente podem aproveitar da aptidão das imagens e dos sons em provocar a implicação emocional do espectador, como bem destaca a historiadora Madeleine Réberioux, após ter assistido em 1967 à projeção de L'anné 1917 de Marc Ferro que "abre diante de nós os horrores da guerra europeia para nos fazer vivê-los...” (REBÉRIOUX, 1968, p.107-110). A imagem sonora confere à história do tempo presente uma dimensão afetiva que, é claro, não é própria dela, mas que é reforçada pela proximidade entre o tempo dos fatos apresentados e o momento de sua historicização. $\mathrm{O}$ acontecimento 
filmado "ao vivo" contribui, mesmo que involuntariamente, com o choque afetivo, quando este é violento e perturbador (as ditas imagens que "podem chocar", como dizem os comentaristas, para afastar as “pessoas sensíveis”). Sob o título de informação, ele suscita frequentemente desconfiança, pois ele é às vezes utilizado, particularmente na televisão, com uma certa complacência de tristeza e dor (podemos neste momento pensar nas imagens da fome na Somália). Mas para além desta dimensão exibicionista, o filme tem a capacidade de fornecer para as pessoas comuns não apenas “o direito de ocupar a mesma imagem”, mesmo se "não têm o direito de ocupar o mesmo lugar social” (RANCIÈRE, 1997, p.51), mas de oferecer a todos uma identidade individual, assim como também coletiva; assim como a possibilidade de manifestar os seus sentimentos, de alegria, às vezes, mas sobretudo, de sofrimento. O filme permite uma “experiência sensível da história” que Arlette Farge, destacadamente, levanta quanto aos filmes de Depardon sobre os marginais, e The Flickering Flame de Ken Loach (1997) insistindo na forma que tem o filme de esclarecer, bem mais que qualquer arquivo, uma realidade histórica muito raramente levada em conta na história do tempo presente (como na do tempo passado), a da emoção de seus atores, que se expressa tanto pelos corpos e rostos enquadrados pelas tomadas cinematográficas quanto pelas palavras pronunciadas.

Vou tomar um exemplo com o ponto de partida de dois filmes realizados paralelamente, La Reprise (1996) e Paroles ouvrières, paroles de Wonder (1997), a partir de uma imagem do "cinema-realidade" rodado em 1968, no centro do que chamamos de os “acontecimentos” de maio, para prestar conta diretamente da greve em uma fábrica de SaintOuen, perto de Paris, que fabricava pilhas da famosa marca Wonder. O autor do primeiro filme, Hervé le Roux marca bem o efeito nele produzido pela imagem audiovisual: “No começo, é uma foto, numa revista de cinema. Um fotograma. A imagem de uma mulher que grita. E depois, um título, a retomada do trabalho nas fábricas Wonder [...] O filme foi rodado por estudantes do IDHEC em 10 de junho de 1968 em Saint-Ouen. Ali vemos operários que voltam ao trabalho após três semanas de greve. E aquela mulher. Que fica lá. Que grita. Ela diz que não vai voltar ao trabalho, que não porá mais os pés naquele inferno. Os anos se passaram. A fábrica foi fechada. Mas não consigo esquecer o rosto desta mulher. Decidi procurá-la. Porque ela só teve direito a uma tomada. E porque eu lhe devo uma segunda”. Assim, seu filme será então de investigação, suscitado pelo efeito emocional de uma tomada direta, para tentar descobrir, a partir e além das imagens, não apenas a heroína (que não foi encontrada), mas também, através dos seus testemunhos e pela forma como os operários e os manifestantes viveram a situação em 68, como sentiram as causas e as consequências da greve 
e da retomada ao trabalho, trinta anos antes. Assim, vemos desenvolver-se uma história sensível do presente, cujos exemplos poderíamos multiplicar.

Em contraposição, no segundo filme, Paroles ouvrières, paroles de Wonder, de Richard Copans, que utiliza as mesmas imagens rodadas em comum para descrever a condição operária em 1968, recusa a subjetividade e a sensualidade sensíveis em La Reprise, deixando parcialmente de lado a dimensão afetiva, e se apresenta como uma tentativa de bem apreender a evolução (ou melhor, o desaparecimento) do mundo operário. Sentimos então como o efeito emocional de um documento audiovisual de origem pode oferecer à história do tempo presente uma forma particular que a autoriza a não estar submetida ao distanciamento tradicional do relato histórico (La Reprise), mesmo se ele não o impede (Paroles ouvrières, paroles de Wonder) e o orienta tanto no sentido da construção memorial quanto na direção de “uma forma de interrogação sobre o presente” na perspectiva descrita por Hartog de um “presente continuado", que absorve o passado para alimentar (ou questionar) o futuro (HARTOG, 2003).

\section{Um presente continuado}

A hipótese de que a imagem cinematográfica só fala ao presente, retomada por Rancière, mas anteriormente formulada pelo semiólogo Christian Metz, lhe permite com efeito de se reapropriar do passado como presente e de colocar em cena a duração. O presente cinematográfico engendra a constituição de uma nova forma de memória imediata, que é menos do passado do que de um presente que absorve em si próprio este passado que não passa e, um futuro imprevisível (ou, infelizmente, demasiado previsível). Tomemos o exemplo de um documentário social cuja forma particular permite interrogar o presente graças a um diálogo direto entre as imagens atuais e as imagens ressuscitadas que reatualizam, alimentando-se dele, um passado suficientemente próximo para ainda estar ativo, por vezes ameaçando um futuro incerto. Les enfants du Borinage, de Patric Jean (1999, Bélgica) denuncia os resultados da destruição da indústria na Europa, ligada à liberalização e à deslocalização, problema cada vez mais grave uma década depois! Em 1993, o documentarista Henri Storck tinha filmado com Joris Ivens um célebre documentário sobre $L a$ Misère au Borinage, fazendo os habitantes daquela região, então mineira e industrial, reviverem os tumultos de 1932, provocados pela morte de 200 mineiros num acidente de trabalho. É um filme militante, um grito de revolta e de denúncia da miséria cujo objetivo é “ilustrar uma ideia política”, o espírito de luta e a tradição de resistência projetados para o 
futuro. O filme de Patric Jean, por outro lado, mostra como este “presente de 1933” mantevese no "presente de 1999" por sua maneira de construir o filme, concebido como um diálogo entre as imagens atuais e as de Henri Storck, acompanhado por “uma carta” a este último, que tinha acabado de morrer e que foi lida em off pelo cineasta. Um rápido exemplo de como ele procede: ele coloca em paralelo catadores iletrados do fim do século 20 e os recolhedores de carvão nos anos 30 e seu comentário, que dá voz aos que não falam (os dois catadores, por exemplo), engaja seu presente pessoal, nele inscrevendo, pela carta a Storck lida por sua própria voz, as imagens do passado (LAGNY, 2007, p. 73-84). Não podemos deixar de sentir a que ponto as fissuras entre o antes e o depois se embaralham e como o testemunho presente, que é o documentário, tanto quanto (ou mais?) um documento (testemunho social) utilizando um monumento (patrimonial, o filme de Storck) torna-se a expressão de um presente glutão que, por não ter liquidado o passado, impede de pensar o futuro a não ser sob a forma de um "presente continuado", este tempo voltado sobre si mesmo "sem solução de continuidade nem revolução” de que fala François Hartog, em seu último capítulo sobre a "dupla dívida: o presentismo do presente” (HARTOG, 2003, p.214-215). Ele interroga assim não apenas a noção de presente, mas também a de história do presente, que só pode falar do presente em relação a um passado ainda vivo e por um futuro do qual ele já está repleto.

A potência do afeto e a hipótese de um presente continuado nos fazem sair do imediato e do factual, ancorando-o na espessura de um tempo capaz de testemunhar o "presente cinematográfico" que se manifesta através dos agenciamentos da imagem audiovisual e do relato fílmico.

\section{Uma poética da história do tempo presente}

Para concluir, podemos pensar, como fazia Kracauer, que o relato histórico deve se recompor em "agenciamentos estéticos” que “conectem o que não tem conexão” e, assim, “apesar de tudo, reforcem a unidade da sequência temporal” (KRACAUER, 2006, p.249). É aí que as qualidades artísticas do filme permitem êxitos particularmente impressionantes. Devo dizer aqui que comecei a me tornar cinéfila assistindo, no fim dos anos 60, a obra de Glauber Rocha, Terra em Transe, que fez com que eu me interessasse pela história brasileira contemporânea. Eu o menciono pelo reconhecimento que tenho a seu respeito, mas não ousaria falar dele após ter ouvido, a seu propósito, as brilhantes análises feitas em Paris por 
Ismail Xavier sobre L'allégorie comme figuration du temps et les formes de représentation de l'histoire!

Vou terminar com uma referência ao filme-poema de Chris Marker Le fond de l'air est rouge, montado para o cinema em 1977 (duração de 4 horas), remanejado diversas vezes e atualizado em 1996-97 para a televisão (duração de 3 horas). Ele apresenta duas vezes, no espaço de uma geração (10 e 30 anos depois), os acontecimentos de 1967-1968 no mundo. Sua descrição desta “onda vermelha” é construída sobre “fatos” atestados por documentos tomados ao vivo que, por sua montagem acompanhada de um comentário em off, relacionam diferentes manifestações de movimentos revolucionários: luta contra a guerra americana no Vietnã, revolução cubana e guerrilha boliviana em 1967, movimentos de revolta e de resistência em Paris, em Praga e em Santiago em 1968. Com uma estrutura (aparentemente) simples que distingue dois períodos correspondentes a duas partes (“As mãos frágeis” e “As mãos cortadas”) e, apoiando-se nestas duas datas, ainda que em forma de flashbacks (pelo menos até 1961) e flashforwards (pelo menos até 1973) e também entrevistas posteriores, que alongam o período enquadrado, numa espessura e duração temporal evocando o "presente continuado”.

O genérico dá conta do projeto em alguns minutos. Ele é construído pela alternância entre planos provenientes do Potemkim e dos planos de luto coletivo, de obséquios populares, de manifestações de revolta e, em seguida, de repressão, certamente atuais e reconhecíveis, mas montadas em série num ritmo que não permite atribuí-los imediatamente a um momento ou a um lugar. O efeito emocional produzido pelas imagens e o ritmo da montagem é acentuado pelo tom às vezes surdo às vezes esplendoroso da música de Berio (Musica Notturna nelle strade de Madrid, variação a partir do quintette 60 de Bocherini) associada no corpo do filme a uma música de referência "política” (Le temps des cerises, composta no fim do século XX pelo socialista Jean-Baptiste Clément) e evidentemente às vozes das pessoas gravadas. Desde o início, tudo corrobora a respeito do posicionamento de Marker ao longo do filme: não apenas o ciclo da violência e da dor, a referência política, mas também o manifesto poético. O genérico de fim dá as referências das fontes, de uma riqueza impressionante e em princípio verificáveis, pois foram tiradas das notícias, dos filmes e de fotos privadas, de folhetos de filmes da época, etc. (em particular das imagens de Fano, Depardon, Reichenbach, Vautier, Klein, dos coletivos os quais participavam Marker, Godard e outros) associados a partes de filmes políticos (do chileno Miguel Littin ou do próprio Marker): a apresentação do canal Arte insiste nisso, chegando a falar "de imagens recuperadas nos cestos de lixo das salas de montagem”. 
Falar de ciência histórica em se referindo ao Le fond de l'air est rouge pode parecer esquisito e até inadmissível. Este filme não é um modelo de "relato de história do presente" para historiadores sérios, mas uma "fábula cinematográfica” que, pelo entrelaçamento de temporalidades distintas e de regimes de imagens heterogêneas, que podem tanto referir-se ao imaginário quanto à realidade, favorece uma análise plural e aberta do tempo presente. Ao contrário do que ocorre nos filmes tradicionais, a imagem não está lá para provar, mas ela age esteticamente: ao longo do filme são as condições de sua fabricação e de sua reutilização que a fazem historicamente testemunhar e, graças tanto à montagem quanto aos comentários em off e à música, permitem a multiplicação dos efeitos de sentido possíveis (e sua livre proliferação). Assim, sem didatismo, está esboçada uma análise crítica que não necessita da intervenção explícita de alguém, mas atém-se ao fato de que o texto fílmico e cinematográfico se oferece ao espectador não como uma série de clichês que diriam a verdade, ou sobre os quais extrairíamos a verdade, mas como vestígios de um mundo que se transforma com ele e que é preciso incessantemente reinterpretar. Uma forma de história, assim, que analisa todo “acontecimento” como um “processo” sempre em curso (MANIGLIER; ZABOUNIAN, 2011) e do qual se permite depreender a seguinte função: fazer sentir a todo instante a permanência do presente.

\title{
AUDIOVISUAL IMAGES AND HISTORY OF THE PRESENT TIME
}

\begin{abstract}
This article written in French was presented as a lecture at the closure of the First International Seminar History of the Present Time, promoted by the Graduate Program in History of UDESC and ANPUH- Santa Catarina, held on November 7-9, 201, in Florianópolis/SC. It presents discussions about the historians' interest for the audiovisual media, at the time when this concept, history of the present time, emerges in France.
\end{abstract}

Keywords: History. Audiovisual images. Present time. 


\section{Referências}

BAECQUE, Antoine de; DELAGE, Christian (dir.). De l'histoire au cinéma. Paris: Editions Complexe, IHTP CNRS, 1998.

BARBERIS, Patrick; CHAPUIS, Dominique. Un cinéaste au service de la Révolution, Roman Karmen, Arte, 2002.

BERTIN-MAGHIT, Jean-Pierre. Les documenteurs des années noires, Les documentaires de propagande, France 1940-44. Paris: Nouveau Monde Éditions, 2004.

CERTEAU, Michel de. L'écriture de l'histoire, Paris, Gallimard, 1975.

COMOLLI, Jean-Louis; RANCIERE, Jacques. Arrêt sur Histoire. Paris: Éditions du Centre Georges Pompidou, 1997.

DELACROIX, Christian; DOSSE, François; GARCIA, Patrick. Les courants historiques en France, 19-20 siècle. Paris: Gallimard, coll. "Folio”, 2007.

FARGE, Arlette. "Ecriture historique, écriture cinématographique”. In: BAECQUE, Antoine; DELAGE, Christian (dir.). De l'histoire au cinéma. Paris: Editions Complexe, IHTP CNRS, 1998.

FERRO, Marc. Autobiographie intellectuelle, avec Gérard Jorland, Perrin, 2011.

FERRO, Marc. Cinéma et Histoire, Paris, Denoël-Gonthier, 1977.

FERRO, Marc. “Le film, une contre-analyse de la société”, Annales ESC, 1973, vol. 28, n¹.

FRANCK, Robert. “Questions aux sources du temps présent” dans CHAUVEAU, Agnès; TETART, Philippe. Questions à l'histoire des temps présents, Éditions Complexe, 1992.

GARCIA, Patrick. "Histoire du temps présent”, dans DELACROIX, Christian; DOSSE, François; GARCIA, Patrick. Les courants historiques en France, 19-20 siècle. Paris: Gallimard, coll. "Folio”, 2007.

GAUDREAULT, André. Cinéma et attraction. Pour une nouvelle histoire du cinématographe, Paris: CNRS, 2008.

HARTOG, François. Régimes d'Historicité, présentisme et expérience du temps. Paris: Seuil, 2003.

KRACAUER, Siegfried. L'Histoire. Des avant-dernières choses, Paris, Stock, 2006, p. 249.

LAGNY, Michèle; ROPARS, Marie-Claire; SORLIN, Pierre. La révolution figurée, Film, Histoire, Politique, Paris, Albatros, 1979.

LAGNY, Michèle, "Le 'genre historique'”, La nascita dei generi cinematografici, a cura di Leonardo Quaresima, Università degli Studi di Udine, Forum Udine, 1999. 
LAGNY, Michèle. "Documentaire et temps présent: le futur en mémoire”, dans BERTINMAGHIT, Jean-Pierre; SELLIER, G. Sellier (org.), La fiction éclatée, t. 1, Paris, INAL’harmattan, 2007.

LINDERPERG, Sylvie ; WIEVIORKA Annette. "Les deux scènes du procès Eichmann”, Annales, Histoire, Sciences Sociales, Cinéma et Histoire, $n^{\circ} 6$, novembro-dezembro de 2008 , p. 1249-1273.

LINDERPERG, Sylvie. Nuit et brouillard, “un film dans l'histoire”, Paris, Odile Jacob, 2007.

MANIGLIER, Patrice; ZABOUNIAN, Dork. Foucault va au cinéma, Paris, Bayard, 2011.

NORA, Pierre. “Le retour de l'événement”, Jacques Le Goff et Pierre Nora, Faire de l'histoire, t. 1, Paris, Gallimard, 1986.

NORA, Pierre. Le débat, L'histoire saisie par la fiction, $\mathrm{n}^{\circ}$ 165, Gallimard, maio-agosto de 2011.

ODIN, Roger. “È giunta l’ora del linguaggio cinematografico”, Bianco e Nero, n 568, Centro sperimentale di cinematografia, Urbino, edizioni del cse, 2011.

REBERIOUX, Madeleine. “Histoire et cinéma: l’année 1917”, Le Mouvement social, $\mathrm{n}$ 62, Janvier-Mars 1968, p.107-110.

RIOUX, Jean-Pierre, "Entre histoire et journalisme”, dans CHAUVEAU, Agnès; TETART, Philippe. Questions à l’histoire des temps présents, Éditions Complexe, 1992.

SORLIN, Pierre. “Clio à l'écran, ou l'historien dans le noir”, Revue d'histoire contemporaine, abril-junho de 1974.

SORLIN, Pierre. Sociologie du cinéma, Ouverture pour une histoire de demain, Paris, Aubier, 1977.

SORLIN, Pierre. European cinemas, European societies, 1939-1990, London, Routledge, 1991. p. 63-70.

THORET, Jean-Baptiste. 26 secondes: L'Amérique éclaboussée. L 'assassinat de JFK et le cinéma américain. Paris: Ed. Rouge profond, 2003.

VERAY, Laurent. L'héroïque cinématographe, documentaire produit avec Agnès de Sacy, INA/ ECPAD, 2002.

VERAY, Laurent. Les images d'archives face à l'histoire, Paris, CNDP-CRDP, 2011. 